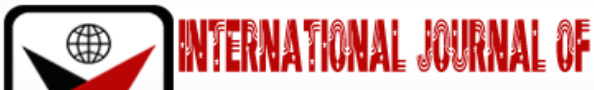 Imas
}

ISSN 2278 - 0211 (Online)

\section{Local Geometric Geoid Models Parameters and Accuracy Determination Using Least Squares Technique}

\author{
Eteje Sylvester Okiemute \\ Ph. D. Candidate, Department of Surveying and Geoinformatics, Nnamdi Azikiwe University, Awka, Nigeria \\ Oduyebo Fatai Olujimi \\ Ph. D. Candidate, Department of Surveying and Geoinformatics, Nnamdi Azikiwe University, Awka, Nigeria
}

\begin{abstract}
:
The absence of national local geoid model in some countries has led to the determination of local geoid model in various parts of those countries. Local geoid models are determined using the geometric and gravimetric methods amongst others. Using the geometric method requires fitting an interpolation surface to points of known geoidal undulations which requires the determination of the geometric geoid model parameters and its accuracy using least squares technique. Because of the rigorous as well as the matrix nature of the technique, researcher have been experiencing difficulty in its application for the determination of geometric geoid models' parameters and their accuracy. This paper presents a detailed procedure for the determination of geometric geoid models' parameters as well as their accuracy using least squares technique. The steps to be considered when applying the technique are enumerated in sequential order. The enumerated steps were also demonstrated with a numerical example.
\end{abstract}

Keywords: Geometric geoid, model parameters, accuracy, least squares

\section{Introduction}

Least squares are a statistical method used to determine a line of best fit by minimizing the sum of squares created by a mathematical function. It is a popular method for determining regression equations. Instead of trying to solve an equation exactly, least squares method is used to determine a close approximation which is known as the estimate. Modelling methods that are often used when fitting a function to a curve include the straight-line method, polynomial method, logarithmic method and Gaussian method. The Least-Squares criterion is an imposed condition for obtaining a unique solution for an incompatible system of linear equations. The term adjustment, in a statistical sense, is a method of deriving estimates for random variables from their observed values. The application of the least-squares criterion in the adjustment problem is called the LeastSquares Adjustment method (Mohammad-Karim, 1981). The method of least squares is a rigorous technique that can be applied to the adjustment of horizontal geodetic network to yield the most likely values of the survey measurements. In geodesy, it is desirable or necessary to fit a plane or curve surface to a set of points with known coordinates or heights. In solving this type of problem, it is first necessary to decide on the appropriate functional model for the data as stated by Ghilani (2010). The decision as to whether to use a plane or curve surface depends on the size of the application area. To determine the best fit surface, two or more surfaces have to be applied and the one with smaller residuals after least squares solution with the surfaces selected.

Geometric geoid models are surfaces that are fitted to the geoidal undulations of an area to enable geoid heights of new points within the area to be interpolated. These surfaces are plane as well as curve surfaces depends on the degree. The curve surfaces are ether quadratic or polynomial in nature. The plane surfaces are usually applied in small areas while the curve surfaces are applied in relatively large areas. The larger the area the higher the order as well as the degree of the polynomial model/surface. To apply any of these models in a particular area, the model parameters as well as its accuracy have to be determined using least squares technique. Obtaining the accuracy of the model enables the reliability of the model to be determined.

Various researchers have been experiencing difficulty in the application of least squares adjustment technique for determination of geometric geoid models' parameters and their accuracy. The difficulty in its application resulted from its matrix nature. The computation of these parameters cannot be handled by Least squares adjustment software as the model terms are not obtained directly from measurement, that is, they are not bearings, azimuth, angles, distances, change in 
northing and easting. They are normally reduced from the variables. Also, the dimension of the coefficient matrix depends on the number of points heights and the order as well as the degree of the model. The general matrix notation of least squares adjustment is simply the sum of the estimate and the matrix of observations equals to the residual matrix. In geoid model parameters determination, the residual is not truly needed. Making the matrix notation of least squares adjustment for geometric geoid parameters determination to be simply observation equal the estimate. Previous studies in which least squares adjustment technique was applied for the determination of local geometric geoid models never presented the breakdown of how the technique was applied in the studies. To determine the reliability of the model, the geoid heights of points from the model are compared with their known geoid heights.

This paper presents step by step application of observation equation method of least squares adjustment technique for determination of local geometric geoid models' parameters and their accuracy.

\subsection{Observation Equation Method of Least Squares Adjustment}

Equations that relate observed quantities to both observational residuals and independent unknown parameters are called observation equations. One equation is written for each observation and for a unique set of unknowns. For a unique solution of unknowns, the number of equations must equal the number of unknowns. Usually, there are more observations (and hence equations) than unknowns, and this permits determination of the most probable values for the unknowns based on the principle of least squares (Ghilani and Wolf, 2006).

Ayeni (2001) and Okwuashi and Asuquo (2014) explained that, in the observations equation method, the adjusted observations are expressed as a function of the adjusted parameter. The functional relationship between adjusted observations and the adjusted parameters as given in Ono et al (2014) is:

$$
L_{a}=F\left(X_{a}\right)
$$

Where, $L_{a}=$ adjusted observations and $X_{a}=$ adjusted parameters. Equation (1) is linear function and the general observation equation model was obtained.

To make the matrix expression for performing least squares adjustment, analogy will be made with the systematic procedures. The system of observation equations is presented by matrix notation as (Mishima and Endo, 2002 and Ono et al, 2018):

$$
V=A X-L
$$

But the residual matrix is not necessary when applying least squares adjustment technique for the determination of local geometric geoid model parameters. Thus, the general matrix notation becomes

$$
L=A X
$$

where, $\mathrm{A}=$ Design Matrix, $\mathrm{X}=$ Vector of Unknowns, $\mathrm{L}=$ Observation Matrix. That is,

$$
A=\left(\begin{array}{cccc}
a_{11} & a_{12} & \ldots & a_{1 n} \\
a_{21} & a_{22} & \ldots & a_{2 n} \\
\ldots & \ldots & \ldots & \ldots \\
a_{m 1} & a_{m 2} & \ldots & a_{m n}
\end{array}\right), \quad X=\left(\begin{array}{c}
x_{1} \\
x_{2} \\
\ldots \\
x_{m}
\end{array}\right) \quad \text { and } \quad L=\left(\begin{array}{l}
l_{1} \\
l_{2} \\
\ldots \\
l_{m}
\end{array}\right)
$$

The determination of the unknown parameters, $X$, requires the normal matrix, $N$ and the matrix of numeric terms, $t$ to be deduced. It is to be noted here that the observations are not weighted.

According to Ghilani (2010), a system of unweighted linear observation equations can be expressed in matrix notation as:

$$
A^{T} A X=A^{T} L
$$

To make $\mathrm{X}$ the subject of the formula, both sides of equation (4) will be divided by $A^{T} A$. Thus,

$$
X=\left(A^{T} A\right)^{-1} A^{T} L
$$

If $A^{T} A=N$, normal matrix and $A^{T} L=t$, matrix of numeric terms, then equation (5) becomes

$$
X=N^{-1} t
$$

\subsection{Accuracy/Reliability of Geometric Geoid Model}

The accuracy of determined local geometric geoid model is obtained using the Root Mean Squares Error, RMSE index. To evaluate the determined local geometric geoid model accuracy, the local geoid model is used to determine the geoidal heights of points whose geoid heights are known. The geometric geoid model geoidal undulations are compared with the 
known geoidal undulations of the points to obtain the residuals. The Root Mean Squares Error, RMSE index for the computation of geometric geoid model accuracy as given by Kao et al (2017) is

$$
R M S E= \pm \sqrt{\frac{V^{T} V}{n}}
$$

Where,

$$
\begin{aligned}
& V=N_{K N O W N}-N_{M O D E L} \text { (Residual) } \\
& N_{K N O W N}=\text { Known geoid height of point } \\
& N_{M O D E L}=\text { Model geoid height of point } \\
& \mathrm{n}=\text { Number of points }
\end{aligned}
$$

\subsection{Bicubic Geoid Model}

The bicubic surface is one of the polynomial geometric geoid models and it is given as

$$
N=a_{o}+a_{1} x+a_{2} y+a_{3} x^{2}+a_{4} y^{2}+a_{5} x y+a_{6} x^{2} y+a_{7} x y^{2}+a_{8} x^{3}+a_{9} y^{3},
$$

Where,

$y=A B S\left(Y-Y_{o}\right)$

$x=A B S\left(X-X_{o}\right)$

$Y=$ Northing coordinates of observed station

$X=$ Easting coordinates of observed station

$Y_{o}=$ Northing coordinates of the origin (average of the northing coordinates)

$X_{o}=$ Easting coordinates of the origin (average of the easting coordinates)

\section{Steps to Be Considered When Computing Geometric Geoid Models Parameters and Accuracy Using Observation Equation Method of Least Squares Adjustment Technique}

The steps to be considered when computing geometric geoid models' parameters and their accuracy using the least squares method are as follow:

- Deduce the coefficient matrix, A, observation matrix, L and matrix of unknown parameters, X from the given or model of interest. It is to be noted here that the geometric geoid model is already established. The coefficients of the model terms on one side of the equation form the matrix of unknown parameters while the terms form the coefficient matrix. The model terms which form the coefficient matrix are deduced from the given variables. The observation matrix is deduced from the term on the other side of the equation as well as the model. The number of points heights deduced with respect to the centroid of the study area determines the number of observation equations. In this, the weights of the observed heights are not truly necessary.

- Having deduced the above stated matrices, the model parameters are computed using equations (6).

- Since the parameters are computed, the next step is to substitute the computed parameters accordingly in the model.

- Having substituted the computed parameters in the model, it (the model) can now be used to develop a program such that the geoid heights of new points in the study area can be determined if the variables of the new points are given.

- The model accuracy has to be computed using equation (7) to determine its reliability. To determine the model accuracy, the geoidal heights of points obtained from the model are compared with their corresponding known geoid heights to obtained the residuals.

\subsection{Numerical Application in Bicubic Geoid Model Parameters and Accuracy Determination}

The ellipsoidal heights of eight benchmarks whose rectangular coordinates and orthometric heights are known were determined using DGPS. The rectangular coordinates, orthometric heights, ellipsoidal heights and the geoid heights as computed from the orthometric and ellipsoidal heights are given in table 1. To interpolate geoid heights of new points, the bicubic geoid model, equation (8) is to be fitted to the computed geoid heights of the benchmarks. Compute the model parameters and accuracy using least squares technique. 


\begin{tabular}{|c|c|c|c|c|c|}
\hline \multirow[t]{2}{*}{ Station } & \multicolumn{2}{|c|}{ Coordinates } & \multirow{2}{*}{$\begin{array}{c}\text { Orthometric } \\
\text { Height, H }\end{array}$} & \multirow{2}{*}{$\begin{array}{c}\text { Ellipsoidal } \\
\text { Height, h }\end{array}$} & \multirow{2}{*}{$\begin{array}{c}\text { Geoidal Height } \\
\text { N (m) }\end{array}$} \\
\hline & Northing & Easting & & & \\
\hline ESO 01 & 249308.287 & 354033.425 & 175.189 & 209.237 & 34.048 \\
\hline ESO 02 & 244533.051 & 278026.486 & 291.686 & 326.581 & 34.895 \\
\hline ESO 03 & 249241.822 & 362785.077 & 222.300 & 256.677 & 34.377 \\
\hline ESO 04 & 259174.974 & 355889.303 & 425.449 & 460.033 & 34.584 \\
\hline ESO 05 & 247210.935 & 359597.719 & 325.386 & 359.665 & 34.279 \\
\hline ESO 06 & 260606.174 & 332700.238 & 120.829 & 155.115 & 34.286 \\
\hline ESO 07 & 252751.094 & 344865.087 & 143.546 & 177.828 & 34.282 \\
\hline ESO 08 & 276864.558 & 374129.027 & 315.314 & 349.689 & 34.375 \\
\hline ESO 09 & 243587.154 & 340245.247 & 257.359 & 291.966 & 34.607 \\
\hline ESO 10 & 269356.441 & 361478.369 & 199.075 & 233.531 & 34.456 \\
\hline ESO 11 & 256457.248 & 357864.254 & 351.273 & 385.448 & 34.175 \\
\hline
\end{tabular}

Table 1: Coordinates and Heights of Benchmarks

Solution

Using equation (9), $Y_{o}$ and $X_{o}$ are computed as the mean as well as the centroid of the given positions as:

$$
\begin{aligned}
& Y_{o}=255371.976 \\
& X_{o}=347419.476
\end{aligned}
$$

Deduction of normal equations using equation (8)

$$
\begin{aligned}
& N_{1}=a_{o}+a_{1} x_{1}+a_{2} y_{1}+a_{3} x_{1}^{2}+a_{4} y_{1}^{2}+a_{5} x y_{1}+a_{6} x^{2} y_{1}+a_{7} x y_{1}^{2}+a_{8} x_{1}^{3}+a_{9} y_{1}^{3} \\
& N_{2}=a_{0}+a_{1} x_{2}+a_{2} y_{2}+a_{3} x_{2}^{2}+a_{4} y_{2}^{2}+a_{5} x y_{2}+a_{6} x^{2} y_{2}+a_{7} x y_{2}^{2}+a_{8} x_{2}^{3}+a_{9} y_{2}^{3} \\
& N_{3}=a_{0}+a_{1} x_{3}+a_{2} y_{3}+a_{3} x_{3}^{2}+a_{4} y_{3}^{2}+a_{5} x y_{3}+a_{6} x^{2} y_{3}+a_{7} x y_{3}^{2}+a_{8} x_{3}^{3}+a_{9} y_{3}^{3} \\
& N_{4}=a_{o}+a_{1} x_{4}+a_{2} y_{4}+a_{3} x_{4}^{2}+a_{4} y_{4}^{2}+a_{5} x y_{4}+a_{6} x^{2} y_{4}+a_{7} x y_{4}^{2}+a_{8} x_{4}^{3}+a_{9} y_{4}^{3} \\
& N_{5}=a_{o}+a_{1} x_{5}+a_{2} y_{5}+a_{3} x_{5}^{2}+a_{4} y_{5}^{2}+a_{5} x y_{5}+a_{6} x^{2} y_{5}+a_{7} x y_{5}^{2}+a_{8} x_{5}^{3}+a_{9} y_{5}^{3} \\
& N_{6}=a_{o}+a_{1} x_{6}+a_{2} y_{6}+a_{3} x_{6}^{2}+a_{4} y_{6}^{2}+a_{5} x y_{6}+a_{6} x^{2} y_{6}+a_{7} x y_{6}^{2}+a_{8} x_{6}^{3}+a_{9} y_{6}^{3} \\
& N_{7}=a_{o}+a_{1} x_{7}+a_{2} y_{7}+a_{3} x_{7}^{2}+a_{4} y_{7}^{2}+a_{5} x y_{7}+a_{6} x^{2} y_{7}+a_{7} x y_{7}^{2}+a_{8} x_{7}^{3}+a_{9} y_{7}^{3} \\
& N_{8}=a_{o}+a_{1} x_{8}+a_{2} y_{8}+a_{3} x_{8}^{2}+a_{4} y_{8}^{2}+a_{5} x y_{8}+a_{6} x^{2} y_{8}+a_{7} x y_{8}^{2}+a_{8} x_{8}^{3}+a_{9} y_{8}^{3} \\
& N_{9}=a_{o}+a_{1} x_{9}+a_{2} y_{9}+a_{3} x_{9}^{2}+a_{4} y_{9}^{2}+a_{5} x y_{9}+a_{6} x^{2} y_{9}+a_{7} x y_{9}^{2}+a_{8} x_{9}^{3}+a_{9} y_{9}^{3} \\
& N_{10}=a_{o}+a_{1} x_{10}+a_{2} y_{10}+a_{3} x_{10}^{2}+a_{4} y_{10}^{2}+a_{5} x y_{10}+a_{6} x^{2} y_{10}+a_{7} x y_{10}^{2}+a_{8} x_{10}^{3}+a_{9} y_{10}^{3} \\
& N_{11}=a_{o}+a_{1} x_{11}+a_{2} y_{11}+a_{3} x_{11}^{2}+a_{4} y_{11}^{2}+a_{5} x y_{11}+a_{6} x^{2} y_{11}+a_{7} x y_{11}^{2}+a_{8} x_{11}^{3}+a_{9} y_{11}^{3}
\end{aligned}
$$

Also using equation (3), the coefficient matrix, A, matrix of unknown parameters, $\mathrm{X}$ and observation matrix, $\mathrm{L}$ are:

$A=\left(\begin{array}{llllllllll}1 & x_{1} & y_{1} & x_{1}^{2} & y_{1}^{2} & x y_{1} & x^{2} y_{1} & x y_{1}^{2} & x_{1}^{3} & y_{1}^{3} \\ 1 & x_{2} & y_{2} & x_{2}^{2} & y_{2}^{2} & x y_{2} & x^{2} y_{2} & x y_{2}^{2} & x_{2}^{3} & y_{2}^{3} \\ 1 & x_{3} & y_{3} & x_{3}^{2} & y_{3}^{2} & x y_{3} & x^{2} y_{3} & x y_{3}^{2} & x_{3}^{3} & y_{3}^{3} \\ 1 & x_{4} & y_{4} & x_{4}^{2} & y_{4}^{2} & x y_{4} & x^{2} y_{4} & x y_{4}^{2} & x_{4}^{3} & y_{4}^{3} \\ 1 & x_{5} & y_{5} & x_{5}^{2} & y_{5}^{2} & x y_{5} & x^{2} y_{5} & x y_{5}^{2} & x_{5}^{3} & y_{5}^{3} \\ 1 & x_{6} & y_{6} & x_{6}^{2} & y_{6}^{2} & x y_{6} & x^{2} y_{6} & x y_{6}^{2} & x_{6}^{3} & y_{6}^{3} \\ 1 & x_{7} & y_{7} & x_{7}^{2} & y_{7}^{2} & x y_{7} & x^{2} y_{7} & x y_{7}^{2} & x_{7}^{3} & y_{7}^{3} \\ 1 & x_{8} & y_{8} & x_{8}^{2} & y_{8}^{2} & x y_{8} & x^{2} y_{8} & x y_{8}^{2} & x_{8}^{3} & y_{8}^{3} \\ 1 & x_{9} & y_{9} & x_{9}^{2} & y_{9}^{2} & x y_{9} & x^{2} y_{9} & x y_{9}^{2} & x_{9}^{3} & y_{9}^{3} \\ 1 & x_{10} & y_{10} & x_{10}^{2} & y_{10}^{2} & x y_{10} & x^{2} y_{10} & x y_{10}^{2} & x_{10}^{3} & y_{10}^{3} \\ 1 & x_{11} & y_{11} & x_{11}^{2} & y_{11}^{2} & x y_{11} & x^{2} y_{11} & x y_{11}^{2} & x_{11}^{3} & y_{11}^{3}\end{array}\right)\left(\begin{array}{l}N_{1} \\ N_{2} \\ N_{3} \\ N_{4} \\ N_{5} \\ N_{6} \\ N_{7} \\ N_{8} \\ N_{9} \\ N_{10} \\ N_{11}\end{array}\right)=\left(\begin{array}{l}34.048 \\ 34.895 \\ 34.377 \\ 34.584 \\ 34.279 \\ 34.286 \\ 34.282 \\ 34.375 \\ 34.607 \\ 34.456 \\ 34.175\end{array}\right), X=\left(\begin{array}{l}a_{o} \\ a_{1} \\ a_{2} \\ a_{3} \\ a_{4} \\ a_{5} \\ a_{6} \\ a_{7} \\ a_{8} \\ a_{9}\end{array}\right)$


Considering equation (3), the above matrices are rearranged as

$$
\begin{aligned}
& L= \\
& \left(\begin{array}{l}
N_{1} \\
N_{2} \\
N_{3} \\
N_{4} \\
N_{5} \\
N_{6} \\
N_{7} \\
N_{8} \\
N_{9} \\
N_{10} \\
N_{11}
\end{array}\right)=\left(\begin{array}{llllllllll}
1 & x_{1} & y_{1} & x_{1}^{2} & y_{1}^{2} & x y_{1} & x^{2} y_{1} & x y_{1}^{2} & x_{1}^{3} & y_{1}^{3} \\
1 & x_{2} & y_{2} & x_{2}^{2} & y_{2}^{2} & x y_{2} & x^{2} y_{2} & x y_{2}^{2} & x_{2}^{3} & y_{2}^{3} \\
1 & x_{3} & y_{3} & x_{3}^{2} & y_{3}^{2} & x y_{3} & x^{2} y_{3} & x y_{3}^{2} & x_{3}^{3} & y_{3}^{3} \\
1 & x_{4} & y_{4} & x_{4}^{2} & y_{4}^{2} & x y_{4} & x^{2} y_{4} & x y_{4}^{2} & x_{4}^{3} & y_{4}^{3} \\
1 & x_{5} & y_{5} & x_{5}^{2} & y_{5}^{2} & x y_{5} & x^{2} y_{5} & x y_{5}^{2} & x_{5}^{3} & y_{5}^{3} \\
1 & x_{6} & y_{6} & x_{6}^{2} & y_{6}^{2} & x y_{6} & x^{2} y_{6} & x y_{6}^{2} & x_{6}^{3} & y_{6}^{3} \\
1 & x_{7} & y_{7} & x_{7}^{2} & y_{7}^{2} & x y_{7} & x^{2} y_{7} & x y_{7}^{2} & x_{7}^{3} & y_{7}^{3} \\
1 & x_{8} & y_{8} & x_{8}^{2} & y_{8}^{2} & x y_{8} & x^{2} y_{8} & x y_{8}^{2} & x_{8}^{3} & y_{8}^{3} \\
1 & x_{9} & y_{9} & x_{9}^{2} & y_{9}^{2} & x y_{9} & x^{2} y_{9} & x y_{9}^{2} & x_{9}^{3} & y_{9}^{3} \\
1 & x_{10} & y_{10} & x_{10}^{2} & y_{10}^{2} & x y_{10} & x^{2} y_{10} & x y_{10}^{2} & x_{10}^{3} & y_{10}^{3} \\
1 & x_{11} & y_{11} & x_{11}^{2} & y_{11}^{2} & x y_{11} & x^{2} y_{11} & x y_{11}^{2} & x_{11}^{3} & y_{11}^{3}
\end{array}\right) \times\left(\begin{array}{l}
a_{0} \\
a_{1} \\
a_{2} \\
a_{3} \\
a_{4} \\
a_{5} \\
a_{6} \\
a_{7} \\
a_{8} \\
a_{9}
\end{array}\right)
\end{aligned}
$$

\begin{tabular}{|c|c|c|c|c|c|c|c|c|c|c|}
\hline S/N & $\mathbf{a}_{\mathbf{o}}$ & $\mathbf{x}$ & $\mathbf{y}$ & $\mathrm{x}^{2}$ & $\mathbf{y}^{2}$ & xy & $\mathbf{x}^{2} \mathbf{y}$ & $x y^{2}$ & $\mathbf{x}^{3}$ & $\mathrm{y}^{3}$ \\
\hline 1 & 1 & $\begin{array}{c}6613 . \\
949\end{array}$ & $\begin{array}{c}6063 . \\
689\end{array}$ & $\begin{array}{c}43744326 \\
.185\end{array}$ & $\begin{array}{c}367683 \\
26.494\end{array}$ & $\begin{array}{l}401049 \\
33.205\end{array}$ & $\begin{array}{c}265251997 \\
452.369\end{array}$ & $\begin{array}{c}243183849 \\
614.972\end{array}$ & $\begin{array}{c}28932275 \\
8332.3\end{array}$ & $\begin{array}{c}222951703 \\
593.398\end{array}$ \\
\hline 2 & 1 & $\begin{array}{c}69392 \\
.990\end{array}$ & $\begin{array}{c}10838 \\
.925\end{array}$ & $\begin{array}{c}48153870 \\
10.672\end{array}$ & $\begin{array}{l}117482 \\
299.097\end{array}$ & $\begin{array}{l}752145 \\
422.811\end{array}$ & $\begin{array}{c}521936195 \\
30177.900\end{array}$ & $\begin{array}{c}815244796 \\
3697.900\end{array}$ & $\begin{array}{l}33415410 \\
0926675.0\end{array}$ & $\begin{array}{c}127338185 \\
0100.930\end{array}$ \\
\hline 3 & 1 & $\begin{array}{c}15365 \\
.601\end{array}$ & $\begin{array}{c}6130 . \\
154\end{array}$ & $\begin{array}{c}23610170 \\
5.266\end{array}$ & $\begin{array}{c}375787 \\
90.293\end{array}$ & $\begin{array}{l}941 \\
05.4\end{array}$ & $\begin{array}{c}144733985 \\
5871.900\end{array}$ & $\begin{array}{r}57742 \\
367.8\end{array}$ & $\begin{array}{r}3627 \\
843\end{array}$ & $\begin{array}{l}3778 \\
463\end{array}$ \\
\hline 4 & 1 & $\begin{array}{c}8469 . \\
827\end{array}$ & $\begin{array}{c}3802 . \\
998\end{array}$ & $\begin{array}{c}71737975 \\
.570\end{array}$ & $\begin{array}{l}144627 \\
92.405\end{array}$ & & $\begin{array}{c}272819364 \\
572.745\end{array}$ & $\begin{array}{r}12245 \\
867\end{array}$ & $\begin{array}{c}60760826 \\
8493.0\end{array}$ & $\begin{array}{r}5500 \\
61\end{array}$ \\
\hline 5 & 1 & $\begin{array}{c}12178 \\
.243\end{array}$ & $\begin{array}{c}8161 . \\
041\end{array}$ & $\begin{array}{c}14830961 \\
1.424\end{array}$ & $\begin{array}{c}666025 \\
93.171\end{array}$ & & $\begin{array}{c}121036084 \\
6490.330\end{array}$ & $\begin{array}{c}811102588 \\
289.749\end{array}$ & $\begin{array}{c}18061505 \\
41087.3\end{array}$ & $\begin{array}{r}54354 \\
687 .\end{array}$ \\
\hline 6 & 1 & $\begin{array}{c}14719 \\
.238\end{array}$ & $\begin{array}{c}5234 . \\
198\end{array}$ & $\begin{array}{c}21665595 \\
6.596\end{array}$ & $\begin{array}{c}273968 \\
26.800\end{array}$ & & $\begin{array}{c}113402013 \\
5309.530\end{array}$ & $\begin{array}{r}40326 \\
149 .\end{array}$ & $\begin{array}{c}31890105 \\
10466.4\end{array}$ & $\begin{array}{c}143400411 \\
060.929\end{array}$ \\
\hline 7 & 1 & $\begin{array}{c}2554 . \\
389\end{array}$ & $\begin{array}{c}2620 . \\
882\end{array}$ & $\begin{array}{c}6524901 . \\
306\end{array}$ & $\begin{array}{c}686902 \\
3.411\end{array}$ & $\begin{array}{c}669475 \\
1.662\end{array}$ & $\begin{array}{c}171009975 \\
69.926\end{array}$ & $\begin{array}{c}175461553 \\
43.902\end{array}$ & $\begin{array}{c}16667133 \\
748.4\end{array}$ & $\begin{array}{c}180029010 \\
64.308\end{array}$ \\
\hline 8 & 1 & $\begin{array}{c}26709 \\
.551\end{array}$ & $\begin{array}{c}21492 \\
.582\end{array}$ & $\begin{array}{c}71340013 \\
4.047\end{array}$ & $\begin{array}{l}461931 \\
073.211\end{array}$ & & $\begin{array}{c}153328107 \\
50101.30\end{array}$ & $\begin{array}{c}123379717 \\
26395.30\end{array}$ & $\begin{array}{c}19054597 \\
523146.2\end{array}$ & $\begin{array}{c}992809138 \\
5353.1400\end{array}$ \\
\hline 9 & 1 & $\begin{array}{c}7174 . \\
229\end{array}$ & $\begin{array}{c}11784 \\
.822\end{array}$ & $\begin{array}{c}51469556 \\
.527\end{array}$ & $\begin{array}{l}138882 \\
033.857\end{array}$ & $\begin{array}{c}845470 \\
08.771\end{array}$ & $\begin{array}{c}606559571 \\
445.613\end{array}$ & $\begin{array}{c}996371464 \\
373.840\end{array}$ & $\begin{array}{c}36925436 \\
6335.649\end{array}$ & $\begin{array}{c}163670007 \\
3254.860\end{array}$ \\
\hline 10 & 1 & $\begin{array}{c}14058 \\
.893\end{array}$ & $\begin{array}{c}13984 \\
.465\end{array}$ & $\begin{array}{c}19765248 \\
2.610\end{array}$ & $\begin{array}{l}195565 \\
256.251\end{array}$ & & $\begin{array}{c}276406418 \\
9287.230\end{array}$ & $\begin{array}{c}274943108 \\
3264.540\end{array}$ & $\begin{array}{l}27787751 \\
76073.390\end{array}$ & $\begin{array}{c}273487544 \\
5700.330\end{array}$ \\
\hline 11 & 1 & $\begin{array}{c}10444 \\
.778\end{array}$ & $\begin{array}{c}1085 . \\
272\end{array}$ & $\begin{array}{c}10909339 \\
5.065\end{array}$ & $\begin{array}{c}117781 \\
4.919\end{array}$ & $\begin{array}{c}113354 \\
23.605\end{array}$ & $\begin{array}{c}118395987 \\
214.349\end{array}$ & $\begin{array}{c}123020157 \\
85.887\end{array}$ & $\begin{array}{r}11394563 \\
32395.640\end{array}$ & $\begin{array}{c}127824933 \\
8.993\end{array}$ \\
\hline
\end{tabular}

Deduction of values of $\mathrm{x}$ and $\mathrm{y}$ for each equation using equation (9) and the computation of coefficient matrix, A elements as presented in table 2 .

Table 2: Computation of Coefficient Matrix, Elements

Computation of the model parameters, $\mathrm{X}$ using equation (6)

Using coefficient matrix, A as well as the computed coefficient matrix, A elements given in table 2 and the observation matrix, $\mathrm{L}$, the model parameters are computed as: 


$$
X=\left(\begin{array}{l}
a_{o} \\
a_{1} \\
a_{2} \\
a_{3} \\
a_{4} \\
a_{5} \\
a_{6} \\
a_{7} \\
a_{8} \\
a_{9}
\end{array}\right)=\left(\begin{array}{c}
34.859077901082436 \\
0.000225556443422 \\
-0.000501234804656 \\
-0.000000030132587 \\
0.000000003398167 \\
0.000000051102750 \\
0.000000000004046 \\
-0.000000000008676 \\
0.00000000000000149 \\
00004302
\end{array}\right)
$$

Substitution of the computed parameters into the interpolation model

Having computed the model parameters, they are substituted into the geometric geoid model. Thus,

$$
\begin{aligned}
N= & 34.859077901082436+0.000225556443422 x-0.000501234804656 y- \\
& -0.000000030132587 x^{2}+0.000000003398167 y^{2}+0.000000051102750 x y+ \\
& +0.000000000004046 x^{2} y-0.00000000000867 x y^{2}-0.000000000000149 x^{3}+ \\
& +0.000000000004302 y^{3}
\end{aligned}
$$

Computation of the model accuracy using equation (7)

The local geometric geoid model whose parameters have been determined was used to obtain the geoid heights of the points and compared with the known geoidal heights of the points to obtain the residual as shown in table 3.

\begin{tabular}{|c|c|c|c|}
\hline Station & $\begin{array}{c}\text { Known Geoidal } \\
\text { Height, } \mathbf{~ ( m )}\end{array}$ & $\begin{array}{c}\text { Model Geoidal } \\
\text { Height, } \mathbf{~} \mathbf{( m )}\end{array}$ & $\begin{array}{c}\text { Difference in Geoid } \\
\text { Height, } \mathbf{\Delta N}\end{array}$ \\
\hline ESO 01 & 34.048 & 34.047 & 0.001 \\
\hline ESO 02 & 34.895 & 34.948 & -0.053 \\
\hline ESO 03 & 34.377 & 34.376 & 0.001 \\
\hline ESO 04 & 34.584 & 34.584 & 0.000 \\
\hline ESO 05 & 34.279 & 34.281 & -0.002 \\
\hline ESO 06 & 34.286 & 34.289 & -0.003 \\
\hline ESO 07 & 34.282 & 34.282 & 0.000 \\
\hline ESO 08 & 34.375 & 34.384 & -0.009 \\
\hline ESO 09 & 34.607 & 34.608 & -0.001 \\
\hline ESO 10 & 34.456 & 34.457 & -0.001 \\
\hline ESO 11 & 34.175 & 34.175 & 0.000 \\
\hline
\end{tabular}

Table 3: Known and Model Geoidal Heights and Residuals

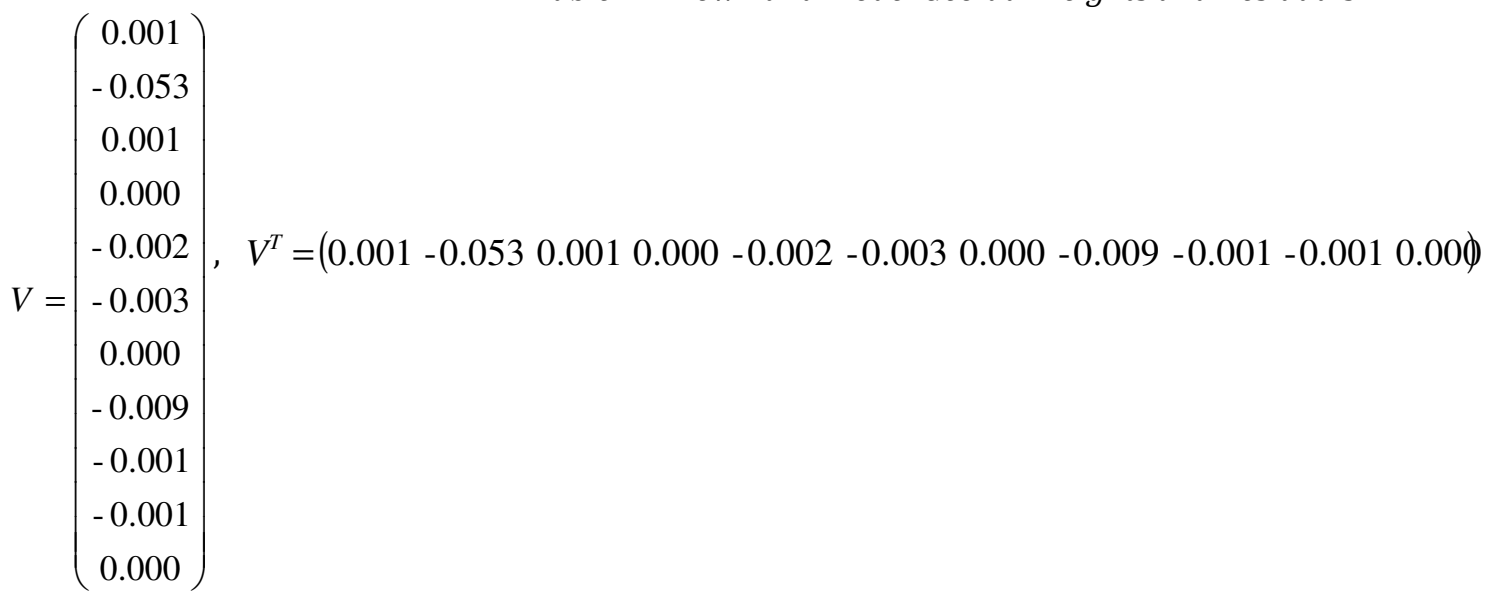


$V^{T} V=\left(\begin{array}{lllllllllll}0.001 & -0.053 & 0.001 & 0.000 & -0.002 & -0.003 & 0.000 & -0.009 & -0.001 & -0.001 & 0.000\end{array}\right) \times\left(\begin{array}{c}0.001 \\ -0.053 \\ 0.001 \\ 0.000 \\ -0.002 \\ -0.003 \\ 0.000 \\ -0.009 \\ -0.001 \\ -0.001 \\ 0.000\end{array}\right)=0.003$

The computed local geometric geoid model accuracy is $\pm 0.017 \mathrm{~m}$.This implies that geoid heights can be interpolated within the application area with accuracy of $\pm 17 \mathrm{~mm}$.

\section{Conclusion}

Considering that fitting a geometric geoid surface to a set of points whose geoidal heights are known to enable the interpolation of the geoid heights of new points if the variables are known requires the determination of the model parameters using the least squares technique which is rigorous and difficult to apply. This paper has presented the step by step procedures to be followed when determining geometric geoid model parameters and its accuracy using the least squares technique. The procedures were demonstrated using a numerical example. Considering the detailed procedures and the numerical example, it is certain that the difficulty in the application of least squares adjustment technique in local geometric geoid model parameters and accuracy determination has been simplified.

\section{References}

i. Ayeni, 0. 0. (2001): Statistical Adjustment and Analysis of Data. A Manual, in the Department of Surveying \& Geoinformatics, University of Lagos, Nigeria.

ii. Ghilani, C. D. (2010): Adjustment Computations: Spatial Data Analysis. Fifth Edition. John Wiley \& Sons, Inc., Hoboken, New Jersey.

iii. Ghilani, C. D. and Wolf, P. R. (2006): Adjustment Computations: Spatial Data Analysis. $\quad$ Fourth $\quad$ Edition. John Wiley \& Sons, Inc., Hoboken, New Jersey.

iv. Kao, S., Ning, F., Chen, C. and Chen, C. (2017): Using Particle Swarm Optimization to Establish a Local Geometric Geoid Model. Boletim de Ciências Geodésicas, Vol. 23, No. 2, pp. 327-337.

v. Mishima, K. and Endo, K. (2002): The Method of the Design for Survey Network by Q Matrices. Proceedings of the 7th International Workshop on Accelerator Alignment, Spring.

vi. Mohammad-Karim, M. (1981): Diagrammatic Approach to Solve Least-Squares Adjustment and Collocation Problems. Technical Report No. 83 of the Geodesy and Geomatics Engineering, University of New Brunswick, UNB, 4400 Fredericton, N. B. Canada E3B 5A3. www2.unb.ca/gge/Pubs/TR83.pdf.

vii. Okwuashi1, O. and Asuquo, I. (2014): Basics of Least Squares Adjustment Computation in Surveying. International Journal of Science and Research (IJSR), Vol. 3, No. 8, pp 1988-1993.

viii. Ono, M. N., Agbo, J. A., Ijioma, D. I. and Chubado, M. (2014): Establishment of Baseline Data for Monitoring of Deformation of Murtala Mohammed Bridge (MMB) Lokoja Kogi State, Using GPS. International Journal of Science and Technology, Vol. 4 No.5, pp 86-92.

ix. Ono, M. N., Eteje, S. O. and Oduyebo, F. O. (2018): Comparative Analysis of DGPS and Total Station Accuracies for Static Deformation Monitoring of Engineering Structures. IOSR Journal of Environmental Science, Toxicology and Food Technology (IOSR-JESTFT), Vol. 12, No. 6, PP 19-29. 